\title{
An Ethnographic study of Culture and Performance in the UK Lingerie Industry
}

\begin{abstract}
This paper examines a particular case of organizational culture, its nature within the work environment, the impact it has on motivation and its interaction with a novel framework of performance measurement. It extends the extant empirical domain of such studies to include a retail unit in the UK lingerie industry. The work is an ethnographic study, and uses participant-observation to focus on the performance framework used and the culture in the unit examined. The evidence shows that a strong culture, in tandem with the innovative package of performance measures in this organization, together lead to enhanced performance. The paper makes an empirical contribution to the literature by using ethnographical evidence on accounting practice, as moderated by organizational culture in this unique setting. From a practical standpoint, it proposes that managers pay more attention to the influence of accounting on organizational culture (and vice versa), when setting performance targets and goals.
\end{abstract}

Keywords Performance, Culture, Ethnography, Participant-Observation, Sociomateriality

\section{Introduction}

The research study of the relationship of culture and performance reported here was based on an explanatory ethnographic case study (cf. Ogbanna \& Harris, 1998; Harris \& Ogbonna, 2002; Ram, 1996), and the setting was a lingerie retailer, selling a wide range of lingerie and sleepwear to varied customers. The company offered a bra-fitting service and all members within the store were trained in this speciality; they actively participated in this area of the job on a daily basis. All the employees were female and they were encouraged to sell the company's products, during the bra-fitting process and also on the shop floor, through communication with customers.

Specifically, the paper examines how a performance measurement framework, unique to this setting, was implemented and used by Head Office, and by the local manager, to measure the financial contribution to the organization of a particular activity within a retail 
outlet. Further, it explored how implementation of this measure both shaped and was shaped by the culture of the organization, leading both to motivational improvements, and to enhanced financial performance.

The paper continues with a brief background to the setting and the company, followed by a review of the relevant literature on performance and organizational culture. A discussion of the research method and methodology is then presented. The performance framework itself is outlined in the subsequent section, as part of the evidence, before the additional fieldwork evidence is introduced, in its various forms, and analysed by section. The discussion then links the theoretical stance to the evidence and previous research. The final conclusion succinctly draws the findings together.

\section{Background}

This paper introduces a novel measure of performance in a unique setting, to provide detailed insight into how the users of this measure incorporated it into their daily working lives, and how it influenced, or was influenced by the culture of their organisation. The particular setting is the UK lingerie market, and the framework for performance measurement is based on the 'Bra-Fit Tracker', which is used to illuminate how a particular aspect of the organization contributed to achieving the strategic goals of the business. The data used to examine this question is primary-source qualitative evidence, gathered by means of interviews, through participant-observation and via ethnographic artefact analysis.

The choice of a retail organisation is particularly interesting, as little empirical evidence yet exists on performance measurement in such an environment. The UK lingerie industry enjoyed modest growth during the peak recession period with a $0.6 \%$ increase between 2008 - 
2012, compared to the womenswear clothing industry, which remained flat. The industry was worth $£ 1.52 \mathrm{bn}$, as at 8 July 2012 (cf. Gallagher, 2012).

The selling technique in the selected UK lingerie retailer was one-to-one and highly personalised. The retail unit was one of a number of like units in a company; sales took place in the context of marketing and promotion; as well as choices of which garments to stock; the sales assistants were not there only to scan items through the till and ultimately to make money for the company; but to introduce the customers to the brand, to inform the customer in detail on elements such as fit, make and style, to provide a brief education and understanding of the products and how they should fit, and to tailor the service to the customer's every need. Whilst the knowledge and expertise provided by this boutique store were not unique in themselves, the layout of the store, the expertise of the staff, their caring approach to sales and their 'personal touch' were marketed as being new and individualistic. This unique selling approach emphasized the requirement for a study focused on the individual and not on the organization as a whole, as sales were driven by the individual, and culture affected the motivation of the employees, who may well have influenced customer retention by their behaviour (cf. Cravens et al., 2015).

\section{Literature Review}

The effect of using a performance measure on performance itself has been discussed extensively in the literature (Banker et al, 2000; Cravens et al, 2015; Ittner et al, 2003; Scott \& Tiessen, 1999); however, it is not exclusive to accounting (Braam \& Nijssen, 2004). Previous work may be split into three broad categories: those exhibiting a positive association between performance measure utilization and performance (Banker et al, 2000; Crabtree \& DeBusk, 2008; Scott \& Tiessen, 1999); those showing a negative association (Ittner et al, 
2003); and those with a mixed impact (Braam \& Nijssen, 2004). Here, an examination is sought of the impact of the use of one UK lingerie retailer's performance measurement framework on the individual performance of the employees. The study was motivated, in part, by Linstead's (1997, p.91) proposal that researchers pay 'closer attention to the underlying nature of the symbolic process, and the way it connects individual understanding, identity and subjectivity to wider power relations through language.' The influence of culture on the relationship of the performance measure and performance (cf. Dent, 1991) is therefore examined. Following Cravens et al (2015), through qualitative assessment, this paper examines how culture in the workplace affected, and was affected by, the performance of employees in a retail setting.

Performance has been defined in various manners (cf. Devinney et al, 2010). Crabtree \& DeBusk (2008), for example, approached performance from a purely financial perspective measuring the impact of the performance measures use on shareholder returns. Some studies have used stock market performance (Ittner et al, 2003) and change in return on investment (Braam \& Nijssen, 2004) for their financial element. From a more subjective standpoint, Ittner et al (2003) examined customer satisfaction or looked at management's overall assessment of the company's performance (Braam \& Nijssen, 2004). Banker et al (2000) and Scott \& Tiessen (1999) utilized a purely non-financial perspective to measure performance ranging from customer satisfaction (Banker et al, 2000) to responses to the organization's expectations (Scott \& Tiessen, 1999).

Goal-setting theory (cf. Hirst, 1987) implies that individuals will work to a higher performance level when they set themselves personal goals that are specific and challenging (Franco-Santos et al, 2012; Grafton et al, 2010); in contrast to, say, having an imposed management accounting and control system, which can detract from other strategic goals 
(e.g. innovation, market leadership) (cf. Werner \& Van der Stede, 1993; Kald et al, 2000; Otley et al, 1995). The idea of setting a goal as opposed to leaving employees to work to the best of their abilities was proven to have a positive effect on motivation in the work of Locke \& Lathham (1990). Leonardi et al (2012) termed this ability to determine and pursue one's own goals 'human agency'.

Despite the treatment of performance measures (e.g. Artz et al, 2012; Banker et al, 2000; Dambrin \& Robson, 2011; Franco-Santos et al, 2012; Groen et al, 2012; Ittner et al, 2003; Ittner \& Larcker, 1998; Scott \& Tiessen, 1999) and organizational culture (e.g. Allaire \& Firsirotu, 1984; Barney, 1986; Booth \& Hamer, 2009; Gillespie et al, 2008; Gordon \& DiTomaso, 1992; Hatch, 1993; Lee \& Yu, 2004; Ogbanna and Harris, 1998, 2002; Pettigrew, 1979) separately, a link between the two concepts has been established (Berry et al, 2009; Dent, 1991; Henri, 2006). Further, there is a body of research which explores the impact or influence of culture on accounting, and vice versa (e.g. Agbejule, 2011; Ahrens \& Mollona, 2007; Busco \& Scapens, 2011; Cravens et al, 2015).

With regard to culture, previous research has examined, for example: organizational change and its effects on organizational culture with an emphasis on the accounting practices involved (Busco \& Scapens, 2011; Dent, 1991); relationships between organizational culture and aspects of performance measures (Cravens et al., 2015; Henri, 2006); organizational subcultures (Ahrens \& Mollona, 2007; Dent, 1991); and the effect of the links between organizational culture and management control systems on performance (cf. Agbejule, 2011; Rotch, 1993). An important finding is that accounting can both influence and be influenced by culture (cf. Agbejule, 2011; Ahrens \& Mollona, 2007; Busco \& Scapens, 2011; Dent, 1991; Henri, 2006). On a related theme, the interactive and diagnostic use of management accounting systems was explored by Simons (1995), and later developed by Tessier and 
Otley (2012). Here, interactive use suggests that management accounting systems (performance measures) are used for 'motivation, focussing organizational attention and encouraging continuous learning' (Agbejule, 2011: 75); whereas diagnostic use employs goal-setting, the measurement of outputs, the comparison of output and original goals to improve performance providing feedback to stay in line with the preset goals (cf. Hirst, 1987; Simons, 2000).

The literature on organizational culture was founded on how it is created, according to Pettigrew (1979), who securely placed sociological and anthropological terms such as 'symbols, languages, beliefs, visions, ideologies, and myths' into the literature on organizations (cf. Linstead, 1997). These terms came to be accepted within the body of work on organizational culture (Barney, 1986; Booth \& Hamer, 2009; Gordon \& DiTomaso, 1992; Hatch, 1993). The interest in organizational culture grew not only in the academic community (Barney, 1986; Pettigrew, 1979; Schein, 2004; Smircich, 1983), but also in the commercial world, when business leaders became aware that organizational culture might have an impact on performance (cf. Barney, 1986; Peters \& Waterman, 1982). Further Peters \& Waterman (1982) explicitly stated that companies with 'strong' organizational cultures also enjoyed high performance. Despite this suggestion of a proposed positive correlation between a 'strong' organizational culture and high performance, until relatively recently the literature has lacked significant empirical evidence.

Instead, some scholars focused their efforts on the development of models (Schein, 2004), and schools of thought in organizational culture (Allaire \& Firsirotu, 1984; Smircich, 1983). Only latterly has empirical evidence begun to appear on the idea of organizational culture being related to performance (Booth \& Hamer, 2009; Gillespie et al, 2008; Gordon \& DiTomaso, 1992; and Lee \& Yu, 2004). More recently, studies have appeared which support 
the positive association of 'strong' organizational culture and high performance (Gillespie et al, 2008; Gordon \& DiTomaso, 1992; Lee \& Yu, 2004).

This paper suggest that a manager has greater motivation to present a more positive view of their organization as a whole than does, say, a lower-level employee (cf. Gordon \& DiTomaso, 1992). It does not simply consider the overall performance of the firm, but rather it recognizes the individual contributions made by employees. As other studies have looked at performance indicators that relate to the whole firm (cf. Booth \& Hamer, 2009; Gillespie et al, 2008; Gordon \& DiTomaso, 1992; Lee \& Yu, 2004) they have tended to disregard individual contribution. Overall performance may depend not only on organizational culture, but also on multiple other factors, including external factors such as the economy, and internal factors such as product innovation. It is for this reason that the focus of this study was on the individual, recognizing that the employee interpreted and created the organizational culture. Without their contribution, the essence of the argument that organizational culture generated wealth for a company would not exist, since good overall performance could be for reasons other than for organizational culture.

'Symbols' arise when 'organizations create visible expressions' (cf. Schein, 2004; Malmi \& Brown, 2008). These expressions can come in the form of the material of the workplace layout and design, or through the necessity to wear a particular uniform or create a certain appearance when working in the organization (cf. Leonardi et al., 2012). Elliott (1994), for example, provided an interesting analysis of the symbolic meaning of brands in an organization. This paper therefore attempts to reveal the symbols in the workplace in question, to determine the intensity of their impact on the employees' involvement in the organizational culture, and further to assess whether this impacted upon performance. 'Clans' were introduced by Ouchi (1979), and given accounting relevance by Dent (1991). 
The concept rests upon 'the idea that individuals are exposed to a socialization process that instils in them a set of skills and values. This socialization process may relate to groups, such as professions (i.e. doctors or accountants), or groups within organizations which form some other kind of boundary, such as an organizational until or division' (Malmi \& Brown, 2008, p.295). This approach to organizational culture complements the methodological stance taken here to include 'social construction' (Berger \& Luckman, 1966; Morgan \& Smircich, 1980), as culture was not thrust upon the individual, but they had a role to play in its creation (cf. Bryer, 2011; Hopper \& Powell, 1985).

\section{Method and Methodology}

Henri (2006) proposed a qualitative approach to the investigation of culture and performance measures, to facilitate the examination of 'diversity of measurement' and 'nature of use'. He emphasised that a quantitative approach may not reveal the richness of organizational culture. In this vein, this paper employs interviews and ethnographic analysis (Linstead, 1997; Ram, 1996) as research instruments, to facilitate an understanding of the intricate nature of management culture (cf. Morales \& Lambert, 2013; Ogbanna \& Harris, 1998; Ram, 1996). Ahrens \& Mollona (2007) recommended the use of ethnography for its ability to reveal through observation aspects of organizational culture and differences between employees in the workplace that might otherwise be obscured. They noted the difference between what people said they did, and what they actually did, implying that interviews may provide the researcher with a potentially unrealistic view of organizational culture in the company. Therefore, the only way to avoid ethnography becoming merely an act of observation and note-taking is to become part of the culture, and to experience it at the same level as the employees (cf. Busco \& Scapens, 2011; Linstead, 1997). 
For data triangulation purposes (cf. Richard et al, 2009), various sources of evidence were gathered. Firstly, an artefact analysis (cf. Ryan et al, 2002) was conducted on the BraFitting training guide [Appendix I]. The depth, descriptions and word choice in the company documentation added to the understanding of the organizational culture, specifically with regard to bra-fitting, but they also gave indications of the training undertaken by the employees. Further, secondly, detailed ethnographic observational notes were taken by one of the researchers, who worked in the store as a participant-observer (cf. Parker, 2008; Myers, 1997), to provide 'in depth, up-close studies of the everyday, routinized, informal activities of the workplace' (Neyland, 2008, p.6). This resulted in a diary covering the busy run-up to Christmas 2012, into the January sales period 2013, and up to the end of February 2013; an extremely busy quarter, with incentives to make bonuses during the Christmas sales, and the need for motivation to continue to sell during the lull in the New Year. Extracts from this diary were used to provide insight into the case. ${ }^{1}$

Thirdly, the final evidence was gathered by means of face-to-face interviews with members of staff at the store, using a semi-structured interview schedule (Appendix III), suitably tailored to shop-floor workers or managers. It focused on the central performance measurement process, the 'Bra-Fit Tracker' [cf. Section 4 above]. Four semi-structured interviews were undertaken as part of this research; with three lower-level employees (two full-timers, FTA and FTB; and one part-timer, PT) and the store manager (SM). The selection of a sample containing a majority of lower-level employees was a deliberate choice to ensure the study remained committed to its nature of appreciating the individual employee and viewing the world as they viewed it in their everyday work environment. This is an advance on the works of Gordon \& DiTomaso (1992), Holmes \& Marra (2002) and Lee \& Yu (2004)

\footnotetext{
${ }^{1}$ See summary of ethnographic observations outlined Appendix II
} 
who took their sample only from management levels. These interviews were semi-structured to allow interviewees to add additional points for discussion (Deslauriers, 1991). The interview instrument was piloted on an independent individual, which highlighted minor issues with the interview questions and allowed for relevant amendments prior to data collection. Interviews varied in length between one-and-a half-hours to thirty minutes, depending on how detailed the responses were and the additional channels of enquiry that emerged from the original questions. A separate room in the store was chosen so that interviewees would feel at ease to speak of their motivational levels. The room was quiet and undisturbed which allowed the interviews to be recorded. Participants gave permission for their responses to be used anonymously.

Whilst the interviews produced in-depth results from the four participants, they failed to highlight the role of interaction between employees, which was important for the methodological position and required understanding of 'clans' (Ouchi, 1979). Observation was therefore required to complement the interview results. Ethnography takes an appropriate view through the eyes of the individual. It also suits the case study format as it permits close analysis of one store within an organisation. Further, as one of the researchers was an employee, and therefore contributed somewhat to the culture of the organisation, the observations have been interpreted through active participation [Participant Observer notes $=$ PO, cf. Appendix II].

Artefacts, defined as 'tangible items, such as formal reports and statements' (Ryan et al, 2002:154) can be used to draw further conclusions and a more detailed picture of the organisational case study. The artefacts used in this case study were company documentation, more specifically, the bra fitting training manual. The depth, descriptions and word choice in the documentation facilitated the understanding of the organisation's 
culture, specifically as it related to bra-fitting and the training undertaken by employees. These might be considered together under the term 'sociomateriality'; 'the collective spaces in which people come into contact with the materiality of an artefact and produce various functions' (Leonard et al, 2012, p.1). Observations and notes on the company documentation were classified by the participant-observer to correspond with the interview categories (cf. Appendix I).

Methodologically, in order to analyse the results each question was examined in turn, focusing initially on the two main aspects of the study, performance measures and organisational culture. Viewing the interviewees' responses as a whole highlighted any differences between responses, any relations to the proposed theoretical lens, interesting and unexpected findings and lines of enquiry for deeper consideration. Observational and company documentation notes, relevant to each category, were viewed as they arose, in analysing the interview responses, in order to add any relevant detail.

The research methods of interviews, ethnographic observations and artefact analysis were fully documented during the data collection process. A step-by-step set of notes was created during the research analysis to ensure that an independent individual could view the notes and be sure of the PO's presence within the organisation and the structured research design for collection and analysis. This fits the definition of 'procedural reliability' in that 'another person could in principle at least, examine what has been done' (Ryan et al, 2002:156). To increase the validity of the evidence method triangulation was employed, as discussed above. 


\section{Evidence}

\subsection{The Performance Measurement Framework}

The Bra-Fit Tracker (cf. Figure 1) was introduced to the store from Head Office about one year before the fieldwork took place, in order to provide middle and senior management with an indication of the contribution being made by the bra-fitting activity. On the face of it, it worked like a traditional performance measure (cf. McKiernan \& Morris, 1994; Singh et al, 2016); beginning with the manager deriving an overall bra-fit target for the week, for the store, based on a percentage of the overall sales target from head office. The girls who work on the shop floor would have a meeting with their shop manager, to discuss their previous week's sales and to agree personal financial targets for the coming week. The staff used the tracker, in tandem with their training guide (cf. Appendix I), as a benchmark for undertaking their daily duties. As sales were concluded, details were entered onto the 'tracker', available for all staff to see, and this open access view is an aspect of the originality of the measure. It included the seller's name, the monetary value, the number of items purchased and any relevant additional comments (e.g. size/colour unavailable, stock-outs). Every evening, individual and team totals were calculated and reported at the subsequent team talk. Figures were calculated to assess the sales' conversion rate, the average transaction values and the average items per customer.

Access to specific numerical records such as individual employee's sales was not permitted. However, permission was granted to indicate whether or not sales targets had been met. With this in mind the following definition was used in the interviews: 'Performance is the individual employee's and manager's expectations regarding bra fit sales'. This allowed the use of non-financial factors to be incorporated, such as, for example, customer satisfaction. This view of performance suits the paper's focus on the individual lower-level 


\subsection{First Impressions: evidence from the researcher (cf. Appendix II)}

The scene is set for the study below, by presenting an unedited extract from the ethnographic notes of the participant-observer's [PO] diary, which describes a typical day in the life of the store.

'The store is immaculate. As soon as you catch a glimpse of the glamorous and sumptuous windows with mannequins dressed in silks, satins and lace, you feel compelled to enter. As you step in the classy and luxurious theme is even more apparent. There are mannequins throughout, dressed in the stores latest offerings. The feminine colour scheme is repeated throughout the store and complements the spacious layout and well-presented sales 
assistants. The girls all wear the same uniform but they look individual with their own style and flair shining through. One girl with voluptuous red lips and short blonde curls, emanating a Marilyn Monroe vibe, converses with another employee dressed in bright purple tights and sparkly gold shoes. It is such a classy and luxurious environment you cannot help but want to buy something from here.

The girls stand throughout the store. They are given a 'position' each hour, like roles in a well-rehearsed play. There is one girl at the door and she is clearly leading the show. She welcomes the customers in with her warm and positive personality shining through, offering assistance during their visit. It is clear from this interaction that the customers are instantly impressed by the level of service and the genuine care for the customer that the girl emits through her body language and interactions with the customers.

The high level of service and attentiveness from the employees continues in the fitting room. One lady has approached me for a bra fitting. I am in the middle of sorting through the delivery but at the sound of her voice I instantly leave it all to one side. I can tell she is nervous as she circled the store a few times before approaching me and as we walk through to the fitting room I can tell just from her body language she is apprehensive. I am professional and use a comforting voice, illustrating that I will be using a sensitive and knowledgeable approach. I have a number of years' experience in bra fitting so I am confident I can get the customer to relax. The tone of my voice is soft and caring as I explain the bra fitting experience before we proceed. During the fitting I ask lots of questions to gain an understanding of the customers' knowledge and needs. She is extremely happy with the bras I have selected for her to try and we have great fun trying on the bras and selecting some for purchase.

Once the bras are selected we approach the till point and I scan the items through while chatting and laughing with my now relaxed customer. The customer gazes in fascination as I wrap her lingerie in a beautiful box and place it into one of our luxurious bags. Before she leaves she looks me in the eyes and says "Thank you so much for your time and your help today". I reply "It is no problem at all, that's what we are here for". We say our goodbyes and the customer leaves the store smiling clutching the bag in her hand. As I watch her leave, I smile, remembering the woman who first approached me, apprehensive and nervous, and look at the confident and happy woman leaving.

It is now around five o'clock and the foot fall is beginning to slow for the day before we close. The girls are spread out around the shop in their designated positions. The customer is always the number one priority for the girls but, now it is quieter, they can also focus more attention on tidying and cleaning. I watch as girls tentatively arrange the wall displays to make them look their best and to the standards the company has outlined. However, watching how the girls approach these tasks and the amount of times they will rehang one bra until it is perfect illustrates that they are not merely tidying just until it is presentable, or because a manager is present on the shop floor. The girls genuinely care; they do not want the store to be perfection, they want their store to be perfection.'

The diary extract above provides insight into the culture and setting of the case.

Through observations it is to be noted that the staff, through their actions, showed a pride in their work. Whilst observation alone can suggest their motivations, it is only through 
questioning that an understanding of their underlying behavioural intentions can be surmised.

The interviews began, therefore, by asking respondents for their understanding of the 'Bra-fit

tracker', and typical answers were given, as follows:

"[It] is like a chart that we fill in for every Bra-fit that we do. You put your name down, you write the sort of shift you are doing for that day, if it is an eight hour shift or a four hour shift. I think that it is purely so that they can monitor how much money you are making in the time that you are in.” [FTB]

The participant-observation diary recorded the following about use of the bra-fit tracker:

"It's been a busy day at the fitting suites; one in, one out, with an emphasis on the bra fit tracker in the team talk, after two previous good days of bra fitting sales. Girls are making an extra effort to write down sales as they are aware of managers watching them. Spotted one employee writing down sales she had remembered from the previous day, so as not to appear to have missed her target. The atmosphere is busy, friendly, feminine; customer is always number one. There are mixed approaches to service but everyone going is for the target. The bra fit target emphasis on its contribution to overall sales is really pushing the girls. The manager is ecstatic about sales the previous day, and sent them to head office on that day to illustrate the bra fit sales contribution" [PO, cf. Appendix II].

This measure of performance was understood by the staff on the work-floor, who saw it as a system for monitoring their individual performance, as well as for how well the store was doing overall. When asked the same question, the store manager answered:

"Our Bra-fit tracker ... is the most important thing that ... we can [use to] make a difference to our sales. It is for me to be able to see what the girls have done ... to report back to head office ... of showing our team off, and if anybody is struggling it is also really good in terms of coaching." [SM]

The store manager saw this as a way, not only of reporting performance, but also of motivating the girls and enabling them to improve; it served as a useful attention-directing tool, in the manner of a typical performance measurement and control mechanism, and she was quick to emphasise its importance by sending good performance results on to Head Office. 
The PO notes give some further detail about the setting of performance targets:

"The target is based on the previous week, the target for the week overall and how the girl has been performing lately. The target will always be realistic but still challenging, they require a great effort from the employees and the targets are unique and individual to the employee. The percentage of bra fits to overall sales for the week are also calculated, and this is also calculated for each day." [PO, cf. Appendix II]

The employees were asked whether they felt better able to meet targets because they were involved in setting them, and gave the following typical response:

"Definitely. Obviously, everyone has good weeks and bad weeks. I think sometimes you get a little bit put off if your target is put too high ... I sometimes think they can be a bit unrealistic and it is a little bit more off-putting. You feel totally de-motivated. I like [targets] to be realistic." [FTB]

The store manager felt that participation in the target-setting process had a motivational impact upon staff, saying:

"I always think about keeping it achievable anyway. I know what people are capable of so, I don't really ever want to be that manager who dictates, and I think, if you have been involved in it, you will feel a bit more inclined to go for it." [SM]

In order to examine whether employees were driven purely by a desire to meet financial targets (Mckiernan \& Morris, 1994), in terms of sales, respondents were asked to clarify what motivated them to perform well. One employee replied:

"You see how you have done the previous week, and then obviously they will raise your target slightly, so you want to be able to get better than that. And that definitely motivates you." [PT]

The impact of not achieving targets is illustrated through one of the diary-notes:

"I hear that during the week we were informed that we did not meet our target so we would not be getting our bonus. The managers are especially disappointed, as it looks like we did not work as hard as we could, when we had actually been in fifth gear since the busy spell started in October on the run-up to Christmas. They are disappointed for the girls as they worked so hard and they do not want it to 
demotivate them, even though it has clearly affected their motivation to some degree. The managers, especially the store manager, are disappointed about the image of the store, compared to others within the same brand. The store manager dreads the question 'why didn't you make it?' from head office.” [PO, cf. Appendix II]

During interviews, the employees were asked explicitly about the use of accounting in the workplace, with typical responses below:

"We focus a lot on sales, and the money ... we know how much we need to make for the day ... [and] the week. I think that money is a big part." [FTA]

"It's the only way to really be able to gauge where the weaker parts of your business are." [SM]

When asked whether bra-fitting meant anything personally or whether it was just a part of the job, one employee responded positively: "It does, I love changing people's opinion of themselves. I like making people feel better" [FTB]. The act of bra-fitting provoked emotional responses from the employees, and observations show that the personal satisfaction gained by changing the customer's self-perception from negative to positive was a driver of motivation to make sales in its own right. Furthermore, the fact that the performance measurement framework was linked to rewards did not appear to motivate the employees. Despite two employees stating that they would be more motivated by the presence of a reward, after further discussion, it was apparent that it was not the reward that motivated, but the competitive nature of the employees: "I think I am really competitive though, I always like to try and win" [FTA].

\subsubsection{Analysis of evidence on performance targets}

The ethnographic observations and fieldwork evidence support goal-setting theory; negotiation between the employees and the manager when setting the next week's bra-fitting target would increase their motivation to work towards it (Franco-Santos et al, 2012; Hirst, 
1987). Through speaking with the store manager and observing the negotiations on targetsetting day in the store the employee appeared to be more focused, as the target was not forced upon them. Instead it became their own through the negotiation stage. This allowed the employees to focus on making the target for themselves, not for the manager (cf. Grafton et al, 2010). Further, the specificity of the goal, as opposed to simply leaving the employees to their own devices, encouraged them to work harder. This is in line with Locke \& Lathham (1990) who suggest that employees will achieve more with set goals rather than with 'try your best' alternatives. The visual aspect of the Bra-Fit Tracker played a large role in this, as the employees were seen to be constantly checking and adding up their figures, and relating these to the target they had agreed. ${ }^{2}$

Informal rewards were sometimes offered for good performance, and these were typically thought to be motivational, even though they might be relatively small. One employee [FTB] explained, for example, that they had a 'plus side', continuing, "some people might view it as ... 'well, there is a reward today, so I am going to try my hardest'”. However, she also pointed out that "we should always be trying our hardest" and that the rewards that worked best for her were 'unknown', for example: "you did so well with your bra-fits today, on your next shift you can go fifteen minutes early". What appealed to her most, therefore, was the 'surprise' ex poste element of the reward "because then you know you have done well, and you have got something for it. You have not thought 'if you do well you'll get this"'. This was consistent with her view that everyone should be doing their best all the time, and not only when they believed that rewards might be available. Further, it

\footnotetext{
${ }^{2}$ Compare this to the sociomateriality of Leonardi et al (2012), whereby people are seen to come into contact with the material artefact (e.g. the bra-fitter), and to perform various functions (e.g. making sales and performing to the best of their ability) according to what the artefact suggests. In this sense, the employees' actions are shaped by their use of the bra-fitter, which has a significant impact upon the way they perform their duties.
} 
complements the notion of a management accounting and performance measurement system being a diagnostic tool for comparing a pre-set target with actual performance (cf. Simmons, 2000; Agbejule, 2011; Otley et al, 1995; Tessier \& Otley, 2012).

When the manager was asked why she thought the company had put the performance measurement system in place she instantly said "Motivation". This illustrates that she thought the interactive nature of the Bra-Fit Tracker to be important; her use of it as a coaching and training tool supports this view (cf. Agbejule, 2011; Grafton et al, 2010; Simmons, 2000; Singh et al, 2016). The constant monitoring and addition of figures and inquisitive attitudes of the lower-level employees illustrate how important achieving their target was to them. When asked if the manager viewing the final results of their progress affected their motivation to work harder, respondents agreed it did: "Yes, I want them to see I am doing well at them and I wouldn't like it if I only had one bra-fit on it and they were seeing it" [FTA].

The motivation of the employees stemmed from the personal relationship created between the bra-fitter and the customer during the bra-fitting encounter and, in turn, with brafitting in general. They were naturally inclined to pursue high sales, a tendency which only happened to be in line with the strategic goals, but which was not necessarily driven by them. Observation showed that the mention of the reward in the team talk by the manager would often spark what appeared to be fake enthusiasm, emphasised by the fact that the employees neglected to mention it again during the day. However, from the lively and competitive chat that surrounded the employees' use of the performance measurement system inference is made that it did indeed encourage their motivation. This provides empirical evidence for Ahn's (2001, p.456) suggestion that performance measures are an 'aid for communicating strategy', rather than necessarily an end in themselves. 


\subsection{Organizational Culture}

In order to examine the culture of this organization, evidence was sought, both from observation and explicitly, through interviews, of values, symbols and clans. According to Cravens et al (2015), a positive workplace culture should recognise a link between performance appraisal and performance. Regarding values, examples were sought of the beliefs and social norms apparent in the organization. One of the full-time employees pointed out the importance of the team's approachability, compared to other stores: "a lot of places you'll go in and you can be kind of intimidated by the staff. But because of our fun and creative looks and personality, we are more approachable, I'd say" [FTA]. Another added that people "come in our store, and we talk to them straight away. Whether they want to 
listen to us or not, we still say hello. We have got a really good team and we all want to be there" [FTB].

One particular value that a full-timer held was 'pride' in the shop and in what they were providing for their customers: "that's why we do the standards; that's why I have three textbooks at home from the company" [FTB]. Another shop-floor worker liked "to give the best experience I can give, and to see customers have a good experience" [PT]. The store manager was able to clarify the culture that the store was aiming for:

"When you walk in here you feel very welcome and the girls are really friendly. They say hello to you, they greet you again. I think we strive for the culture of warm, welcome, friendly, approachable. It is a very sensitive issue - lingerie - and people can get embarrassed with it, and I think because we are so comfortable with it, it can come across ... we are the only shop on the high street that is actually using customer service to get money." [SM]

Values were also used by management to control the behaviour of employees in this store: "All the training tells you how to behave in work" [FTA] (cf. Appendix I). The store manager explained further that "the training at the beginning was very much a focus on making your customer feel comfortable, so dealing with that can be quite sensitive. It's not customer service in the way that you are nice to people; it is going above and beyond, and making them feel special" [SM]. Further, employee interaction helped to pass on values to employees, informally:

"From certain employees I feel like I have gained lots of knowledge; they have taught me a lot. I feel like I [contribute] quite a bit, because I am happy and I try and make everyone else feel the same" [FTA].

"If they [staff] come in and are hyper and happy and excited, then it just makes for a much better atmosphere in store. There is a way of management approaching [an employee] and I think our attitudes have a huge impact. [We] follow the lead. They [colleagues] taught us not just a skill that was black and white, and they taught us how to treat a customer properly, and how to make them feel comfortable in themselves"[SM]. 
"The colour scheme, it's spread throughout the whole store, you see it everywhere the kind of quirky look. It's not just the fact that we wear the same uniform, but the fact that they try and dress us up a bit different, so we don't just look like we are wearing a plain uniform." [FTA]

"With the dress code ... I like how it has relaxed a little ... it's become more individual ... you come into our store and everybody has made a little bit more effort for the day. Our windows promote us more. Having the massive window in [the shopping centre] - that was amazing, and having the lifts decorated. I think it makes us different from other brands in the market and, well, we do offer something for everyone." [FTB]

"It is nice and clean looking, and it's quite attractive. I would not go into a shop that didn't look nice." [SM]

"I think little things make a difference to the customer, like the fact that we have the 'help' button in the fitting room, and the lights [different colour themes] - a lot of people are amazed by that, they love that." [PT]

The store manager commented on the individuality of the girls in her store, as follows:

"I think it makes an impact on staff morale. For the employees who can be quite quirky outside of work, then it is quite nice not to have to cover up your tattoos, take out your piercings, not to take off your scarf, not to have to take off your nail polish, and totally repress your personality." [SM]

Interviewees were asked whether there was anything that could be classified as a 'clan', either within the lingerie industry, the retail sector, their own store and/or other stores in the brand. Recall that clans arise from 'the idea that individuals are exposed to a socialization process that instils in them a set of skills and values' (Malmi \& Brown, 2008). Within lingerie, there are certain expectations about behaviour that might not be necessary in other sectors, as the respondents explained, for example: 
"Obviously, we have to be a bit more discreet because we work in lingerie - we can't be as open as when you're selling a T-shirt - you can't just bring it out to the customer and say 'here, this is yours!'” [FTA]

Beyond that, there were the company rules and memes, which the girls adopted in their customer relations:

\begin{abstract}
"We'll probably all be quite similar in the fact we will stick to the same rules when we're selling, and things like that, we know all the same techniques ... it definitely helps having that wee bit of extra knowledge from what the other stores have got." [FTA]
\end{abstract}

"What sets us apart from the others is our knowledge" [FTB]

"That we care about the customers is the big difference." [PT]

\title{
5.3.1 Analysis of evidence on organizational culture
}

'Values' (Simons, 1995) in the organization tended to relate to the employees approach to customer service. From the training manuals, customers were the 'number one priority', entitled to a 'high standard experience' and 'courteous, professional, experienced and polite' behaviour. The employees reflected these values through their approach to service, so the firm did appear to have some influence over their behaviour. An observer might understand this to be an 'operation of rule-like activities' (Morgan \& Smircich, 1980), imposed on employees by the organization. However, each used her own flair and unique approach to customer service. The company set out their expectations and the staff improvised, using their own initiative. They also had a personal connection to customer service, so they acted in their own interests as well as in those of the company, thus providing evidence of goal congruence. Further, the helpful nature between the team members had aided the team in becoming "like a little family" (SM). 
The employees took great pride in the store, as they attended to it with care and wanted it to look its best at all times. The visual elements created an atmosphere in the store and an attitude to which employees could adhere (cf. Leonardi et al, 2012). This was apparent through their own visual expressions, their hair, make-up and accessories. The employees often wore heels and always looked presentable with their own quirky touches added. Despite the company probably putting the visual aspects in place to encourage customers to spend, the employees themselves were affected by it the most. The reasons for the clans being present in this store vis-à-vis other stores in the company, were related to the values and symbols created by the employees, and not the company. The part-time worker summed up what differentiated them from others, saying simply that it was "the girls".

\subsection{A Culture-Performance Link}

As a supplement to the participant-observation, and in order to address the issue of organizational culture and performance measures, the four interviewees were asked to imagine three hypothetical scenarios. In scenario one the organizational culture retained the status quo, but the formal performance measurement system was removed, placing a reliance on the organizational culture and the employees' own personal drive to push performance. What would be the effect on the employees' motivation, when placed in this hypothetical scenario? There was some agreement that performance would slip overall, tempered to a degree by comments as below:

"I think I would still personally want to try my hardest, and I feel like, if we didn't have the tracker, I would probably ... set myself little targets, just so I would know that I was still performing to the best of my ability." [FTA]

"I think people wouldn't try as hard because people are not going to notice if your name is not on the sheet. You are going to get people who ... think, 'well, no-one is going to notice that I have not done any bra-fits' because there is nothing to stop them." [PTB] 
"I think we would see a dip [in performance]." [SM]

"I think it would affect you, because most people like to know how they are going ... everyone likes a pat on the back now and again." [PT]

Scenario two asked the respondents to imagine that the performance measurement system remained in place, but that the organizational culture were different. Now the customer was no longer their top priority and the level of customer service was significantly lower. Given this scenario, there was agreement amongst employees that the level of service and performance would deteriorate:

"I think, if we weren't motivated to provide the service that we do, a lot of people ... would probably let it slide ... you probably wouldn't put all your sales down, you probably wouldn't try as hard" [PTA].

"I don't think I would be as confident, so I think that would put me off a little bit. I might feel like I was doing something that they wouldn't like us to do, as a company" [FTB].

"[Sales] would be terrible; we would have a lot of refunds" [SM].

This illustrates the strength of the influence that organizational culture had on individual performance. It also indicates that employee adoption of the company organizational culture was important as the customer was influenced by the individual more than the company in this bra-fitting environment. This was prevalent in the interviews too, with one full-time employee instantly stating "the customer's number one". The employees not only gave the customer priority, they delivered a first-class "customer experience" (PT).

Scenario three proposed a regular day in the store, with the performance measurement system and organizational culture at a status quo. All respondents agreed without hesitation that the best performance would occur when both organizational culture and the formal performance measurement system were present. For example: 
"I think all of that together is contributing to the service we're providing." [FTA]

"It is that visual, of seeing how well you are doing. ... I like to give the best experience I can give and, being in here, obviously, you are pushed to do that anyway. But I just like to see customers have a good experience." [PT]

All interviewees agreed that there was an organizational culture in the store which made it unique from their competitors. This demonstrates that employee effort and adoption of the organizational ethos was crucial in creating a 'strong' organizational culture. It further implies that, during the busy periods, when employees might perform slightly below standard, the culture in turn would also suffer.

\subsubsection{Analysis of a culture-performance link}

Employees wanted the manager to view them as doing well for their own personal benefit, but it also appeared that they valued the manager's opinion of them. This stemmed from the close-knit relationship the manager had with her lower-level employees and the open lines of communication. The feedback and subsequent learning opportunity the system of performance measurement offered to the manager and her employees was aided by the ease in communication between both parties (Ahn, 2001). The facilitation of communication and the motivational effects of the measure are consistent with Malina \& Selto (2001) who found that poor communication in turn leads to demotivation. The increase in motivation with the use of the performance measurement system in place is consistent with previous studies, including Banker et al (2000) and Crabtree \& DeBusk (2008), both of which noted a link between performance measure implementation and performance. This study therefore leads us to a different conclusion to that of Ittner et al (2003) that implementation of a performance measure can actually impair performance. 


\section{Discussion}

This paper has presented and analysed above evidence on the setting of performance targets, the culture within the case under consideration, and the existence of a link between culture and performance. Evidence was presented that a performance measurement system was implemented through the use of the Bra Fit Tracker, which although embodied in a procedural document, was central to the determination of targets, and was used interactively, on a real-time basis, by employees to constantly monitor and update their progress against both their own specific targets and performance of their colleagues. The culture within this organization, and this retail outlet in particular, was apparently strong, and each worker had their own clear view of what that culture was, and how they fitted in. Analysis suggests that the performance measurement system which was in place had a positive motivational impact upon performance; this was not always explicit, but was occasionally implicit through observation of the employees' actions and/or reactions to events.

Observation of practice in this store suggested that the use of the material performance measurement system, which incorporated a visual aid for the employees, was key to encouraging high performance, as measured by their ability to conclude sales and to provide an exceptional 'customer experience' (cf. Leonardi et al., 2012). Rewards, in themselves, did not motivate these employees, but the competitive nature they encouraged had a positive impact on their social interaction and, subsequently, on performance. Overall, better performance was generally encouraged when both organizational culture and a system for measuring performance were in place and well aligned (cf. Woods, 2012). The presence of the performance measurement system in this lingerie store had a positive motivational impact, which in turn led to higher performance for individual employees. The concrete and visual aspect of the performance measurement framework and the ability to view their 
progress in bra-fit sales on paper, helped to concentrate the employees' focus on their individual targets.

One particular performance measurement system, the bra fit tracker, was used extensively in the store, by all of the staff, to monitor the salesperson's own performance, against pre-determined individual targets, and to present an overall picture of performance for the store, as returned to Head Office. It was unique in three respects: firstly, perhaps its best feature was its flexibility: it could be tailored to individuals, and changed from week to week, to incorporate growth and learning, as well as both financial and non-financial measures, which would be of use both to the individuals constituting the workforce and to the store manager; or it could be used to monitor store performance, and ultimately manager's performance, against other stores in the group, which would be of use both to the manager and to Head Office. Secondly, the individual whose performance was being measured was heavily involved in determining their own targets for the period to come. Whilst it did incorporate objective measures, it also recorded subjective assessments of customer satisfaction. Thus it allowed the store's and individual's culture to be reflected in the measure. And thirdly, the tracker was freely available for all to see, thus encouraging competition for higher achievement.

Organizational culture significantly affected the way these employees behaved, but the existence of the performance measurement system itself also influenced employee brafitting performance. The social values within this organization were cultivated and enhanced through membership of their workforce. Here, the individual had influence and created their own reality, but they still were influenced by the organizational values of the company (cf. Morgan \& Smircich, 1980; Ogbanna \& Harris, 1998). First, they were socialised into 'behaving' in the way the company wished them to (Bruggeman \& van der Stede, 1993; 
Leonardi et al., 2012; Rotch, 1993). However, they were also 'thinking' and interpreting the experience. Whilst all interviewees agreed that 'symbols' were created between them as a team, they felt that their appearance and efforts were much better than in other stores within the same company. Their own interpretation and creation of the nominal organizational symbols allowed then to modify the store's organizational culture and permitted them to behave in an individualistic fashion.

Despite the presence of an unavoidable influence from the organization, this in itself does not create the organizational culture; and it is observed here that the individual in this setting was the culture creator, which describes aptly the process of culture creation within this UK lingerie retailer. A tentative suggestion is therefore that there is evidence of a 'strong' organizational culture (cf. Gillespie et al, 2008; Lee and Yu, 2004) within this setting; culture is unique to the store and customers remember it through interaction with its values, symbols and clans (cf. Elliott, 1994; Hatch, 1993).

The following key points that are particularly relevant to this setting might be drawn from this study. First, workplace culture had a clear impact upon how the employees used and reacted to the performance measurement framework. The organisation had attempted to generate a culture which created for the customer an 'experience, something for our customers to remember, that invokes emotion, soft, sincere, caring, polite and positive' (cf. Appendix I). These were all suggestions about how the service should be provided. The staff had interpreted this as also including the visual aspect of the experience (cf. '5.1 First Impressions', Appendix III, and the discussion of 'symbols' in Section 5.2, above). In this sense, the 'material' was incorporated in the presentation of the store itself, the way the employees were dressed and made up, and the 'look' or 'feel' of the goods on offer. The 
social practices were, to some extent, shaped by the rules and structure of the organisation, 
This paper has appreciated the individual contribution of the employee. By placing equal importance on organizational culture and performance measures it has uncovered not only elements of the culture, but also accounting implications that, without some concentration on culture, might have been ignored. One suggestion to be made, from a practical standpoint, is that managers should consider the organizational culture of the company before implementing a system for performance measurement, as the success observed in this case came from aligning the performance measurement framework with organizational culture. Further, when setting performance targets, managers should be aware that accounting can influence and be influenced by organizational culture, as the link may not always be obvious.

This paper has made a qualitative contribution to the literature on culture and performance in a unique organisational setting; a lingerie retail outlet. It has provided novel insight into a system of performance measurement which is unique to that setting, the bra-fit tracker, through a mix of data, gathered from interview evidence with the individuals affected by this measure, ethnographic analysis of various artefacts including organisational literature, and through participant-observation. A strength of the paper and its evidence is that it shows that the relationship of culture, targets, performance measurement, reporting, analysis and rewards are subtle, intricate, reflexive and shifting, and are influenced through enactment by the employees and manager in the store. Undertaking this ethnographic study in an accounting context has provided supportive documentary knowledge of how culture can affect performance and its measurement. A further strength is therefore the insight that this ethnography provides.

A limitation of the study is that the results are not generalizable, given that they are based on a single case study retail outlet within a larger organization. However, they do 
contribute to a growing area of study that will facilitate future interpretation and comprehension of the link between culture and performance, and may in due course contribute to a shift in practice, once that further understanding is available. To that end, replication would be a useful first point of action; analysing further outlets within the same organization, and then within competitor organizations, to see where the differences and similarities lie should provide additional useful insight. Further, specific sales data for individuals, along with completed Bra Fit Trackers for the stores would allow issues of causality to be addressed; ultimately, this might provide insight into a clear link between specific aspects of culture and performance. Using this study as a guide, from which to build a more highly specified research instrument, administered to a larger sample, would strengthen support for the findings of this work. Finally, the study could be adapted to examine additional retail types, for example, luxury clothing, in order to examine whether the findings on culture stand up in alternative settings.

\section{Conclusion}

This study set out to investigate whether a link could be established between the culture of a lingerie retail outlet and the performance of its employees. It sought to do so by the use of ethnographic methods, involving the analysis of company documentation, and participantobservation, noted in the form of a diary, and supported by additional primary-source data from evidence with key actors, such as members of sales staff and the store manager. Broadly, the findings were that the store's employees were socialised, both through the organization's expectations and their own individualism into creating a strong and positive culture, and that this had a role to play in the performance of staff; and that accounting 


\section{References}

Agbejule, A. (2011). 'Organizational culture and performance: the role of management accounting system', Journal of Applied Accounting Research, 12(1), pp.74-89.

Ahn, H. (2001). 'Applying the Balanced Scorecard Concept: An Experience Report', Long Range Planning, 34(4), pp.441-461.

Ahrens, T. and M. Mollona (2007). 'Organisational control as cultural practice-A shop floor ethnography of a Sheffield steel mill', Accounting, Organizations and Society, 32(4), pp.305-331.

Allaire, Y. and M.E. Firsirotu (1984). 'Theories of Organizational Culture', Organization Studies, 5(3), pp.193-226.

Banker, R.D., G. Potter and D. Srinivasan (2000). 'Empirical Investigation of Plan that Includes an Incentive Nonfinancial Performance Measures', The Accounting Review, 75(1), pp.65-92.

Berger, P.L. and T. Luckmann (1966). The Social Construction of Reality: A Treatise in the Sociology of Knowledge. New York: Anchor Books, 1st Edition.

Booth, S.A. and K, Hamer (2009). 'Corporate culture and financial performance: an empirical test of a UK retailer', International Journal of Retail \& Distribution Management, 37(8), pp.711-727.

Bruggeman, W. and W. van der Stede (1993). 'Fitting management control systems to competitive advantage', British Journal of Management, 4(3), pp.205-218.

Bryde, D.J. (2005). 'Methods for managing different perspectives of project success', British Journal of Management, 16(2), pp.119-131.

Bryer, A.R. (2011). 'Accounting as learnt social practice: The case of the empresas recuperadas in Argentina', Accounting, Organizations and Society, 36(8), 478-493.

Busco, C. and R.W. Scapens (2011). 'Management accounting systems and organisational culture: Interpreting their linkages and processes of change', Qualitative Research in Accounting \& Management, 8(4), pp.320-357.

Crabtree, A.D. and G.K. DeBusk (2008). 'The effects of adopting the Balanced Scorecard on shareholder returns', Advances in Accounting, 24(1), pp.8-15. 
Cravens, K.S., E.G. Oliver, S. Oishi, and J.S. Steward (2015). 'Workplace culture mediates performance appraisal effectiveness and employee outcomes: a study in a retail setting', Journal of Management Accounting Research, 27(2), pp.1-34.

Elliott, R. (1994). 'Exploring the symbolic meaning of brands', British Journal of Management, 5(s1), pp.S13-S19.

Franco-Santos, M., L. Lucianetti, L. and M. Bourne (2012). 'Contemporary performance measurement systems: A review of their consequences and a framework for research', Management Accounting Research, 23(2), pp.79-119.

Gallagher, V. (2012). 'Lingerie welcomes its secret weapon', Available at: http://www.drapersonline.com/news/analysis/lingerie-welcomes-its-secretweapon/5040319. article [Accessed on 31st December 2012].

Gillespie, M.A., D.R. Denison, R. Smerek and W.S. Neale (2008). 'Linking organizational culture and customer satisfaction: Results from two companies in different industries', European Journal of Work and Organizational Psychology, 17(1), pp.112-132.

Gordon, G., and N. DiTomaso (1992). 'Predicting corporate performance from organizational culture', Journal of Management studies, 26(6), pp.783-798.

Grafton, J., A.M. Lillis and S.K. Widener (2010). 'The role of performance measurement and evaluation in building organizational capabilities and performance', Accounting, Organizations and Society, 35(7), 689-706.

Harris, L.C. and E. Ogbonna (2002). 'The unintended consequences of culture interventions: A study of unexpected outcomes', British Journal of Management, 13(1), pp.31-49.

Hatch, M.J. (1993). 'The Dynamics of Organizational Culture', The Academy of Management Review, 18(4), pp.657-693.

Henri, J.-F. (2006). 'Organizational culture and performance measurement systems', Accounting, Organizations and Society, 31(1), pp.77-103.

Hirst, M.K. (1987). 'The effects of setting budget goals and task uncertainty on performance: a theoretical analysis', Accounting Review, 774-784.

Hopper, T., and A. Powell (1985). 'Making sense of research into the organizational and social aspects of management accounting: A review of its underlying assumptions', Journal of Management Studies, 22(5), pp.429-465.

Ittner, C.D., D.F. Larcker and T. Randall (2003). 'Performance implications of strategic performance measurement in financial services firms', Accounting, Organizations and Society, 28(7), pp.715-741.

Kald, M. F. Nilsson and B. Rapp (2000). 'On strategy and management control: the importance of classifying the strategy of the business', British Journal of Management, 11(3), pp.197-212.

Lähdesmäki, M. and M. Siltaoja (2010). 'Towards a variety of meanings-multiple representations of reputation in the small business context', British Journal of Management, 21(1), pp.207-222.

Lee, S.K.J. and K. Yu (2004). 'Corporate culture and organizational performance', Journal of Managerial Psychology, 19(4), pp.340-359. 
Leonardi P.M., B.A. Nardiand J. Kallinikos (2012). Materiality and Organizing: social interaction in a technological world. Oxford Scholarship Online. DOI: 10.1093/acprof:oso/9780199664054.001.0001.

Linstead, S. (1997). 'The social anthropology of management', British Journal of Management, 8(1), pp.85-98.

Locke, E.A., and G.P. Lathham (1990). A Theory of Goal Setting and Task Performance. Englewood Cliffs, NJ: Prentice-Hall, 1st Edition.

McKiernan, P. and C. Morris (1994). 'Strategic planning and financial performance in UK SMEs: does formality matter?’, British Journal of Management, 5(s1), pp.S31-S41.

Malina, M.A. and F.H. Selto (2001). 'Communicating and controlling strategy: an empirical study of the effectiveness of the balanced scorecard', Journal of Management Accounting Research, 13(1), pp. 47-90.

Malmi, T. and D.A. Brown (2008). 'Management control systems as a packageOpportunities, challenges and research directions', Management Accounting Research, 19(4), pp.287-300.

Morales, J. and C. Lambert (2013). 'Dirty work and the construction of identity. An ethnographic study of management accounting practices', Accounting, Organizations and Society, 38(3), pp.228-244.

Morgan, G., and L. Smircich (1980). 'The case for qualitative research', Academy of Management Review, 5(4), pp.491-500.

Myers, M.D. (1997). 'Qualitative research in information systems', Management Information Systems Quarterly, 21(2), pp.241-242.

Neyland, D. (2008). Organizational Ethnography. London: SAGE Publications, 1st Edition.

Ogbonna, E. and L.C. Harris (1998). 'Managing organizational culture: compliance or genuine change?', British Journal of Management, 9(4), pp.273-288.

Otley, D., J. Broadbent and A. Berry (1995). 'Research in management control: an overview of its development', British Journal of Management, 6(s1), pp.S31-S44.

Ouchi, W., (1979). 'A theoretical framework for the design of organizational control mechanisms', Management Science, 25(9), pp.833-848.

Parker, L.D., (2008). 'Boardroom Operational and Financial Control: an Insider View', British Journal of Management, 19(1), pp.65-88.

Peters, T.J., and R.H. Waterman Jr (1982). In Search of Excellence: lessons from America's best-run companies. New York: Harper Row, 1st Edition.

Ram, M. (1996). 'Uncovering the Management Process: An Ethnographic Approach', British Journal of Management, 7(1), pp.35-44.

Richard, P.J., T.M. Devinney, G.S. Yip and G. Johnson (2009). 'Measuring organizational performance: Towards methodological best practice', Journal of Management, 1-87.

Rotch, W. (1993) 'Management Control Systems: One View of Components and Their Interdependence', British Journal of Management, 4(3), pp.191-203. 
Ryan, B., R.W. Scapens and M. Theobald (2002). Research Method and Methodology in Finance and Accounting. Hampshire: South-Western CENGAGE Learning, 2nd Edition.

Schein, E.H. (2004). Organizational Culture and Leadership. San-Francisco: Jossey-Bass, 3rd Edition.

Simons, R. (1995). Levers of Control. Boston: Harvard University Press, 1st Edition.

Simmons, R. (2000). Performance Measurement and Control Systems for Implementing Strategy: Prentice Hall; New Jersey, USA.

Singh, S., T.K. Darwish and K. Potocnik, K. (2016). 'Measuring Organizational Performance: A Case for Subjective Measures', British Journal of Management, 27 (1), 214-224.

Smircich, L. (1983). 'Concepts of culture and organizational analysis', Administrative Science Quarterly, 28(3), pp.339-358.

Teerikangas, S. and P. Very (2006). 'The culture-performance relationship in M\&A: From yes/no to how', British Journal of Management, 17(S1), pp.S31-S48.

Tessier, S. and D. Otley (2012). 'A conceptual development of Simons' Levers of Control framework', Management Accounting Research, 23, 171-85.

Turnbull, S. (2001). 'Corporate ideology - meanings and contradictions for middle managers', British Journal of Management, 12(3), pp.231-242.

Woods, A. (2012). 'Subjective adjustments to objective performance measures: The influence of prior performance', Accounting, Organizations and Society. 
Figure 1: The Bra Fit Tracker

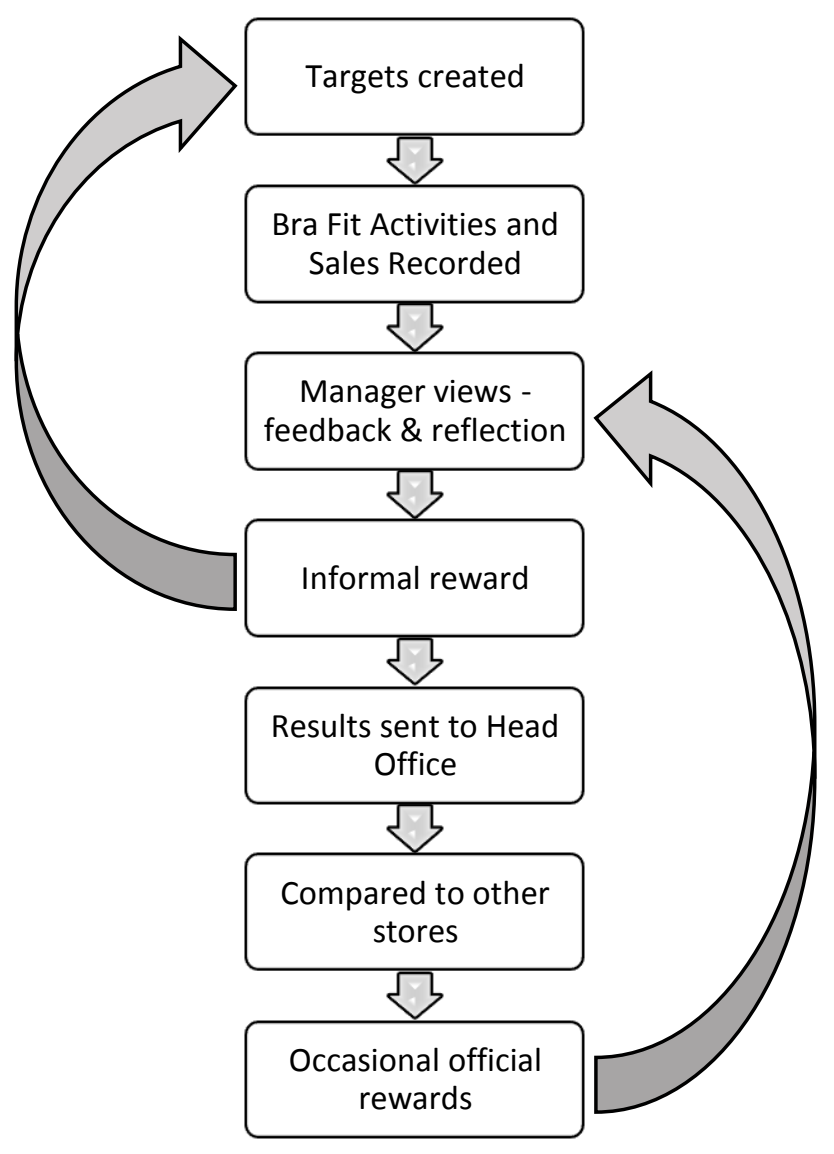




\section{$\underline{\text { Appendix I }}$ \\ $\underline{\text { Artefact Analysis for the Bra Fitting Training Guide }}$}

\section{Common Words and Phrases}

'experience', 'something for our customers to remember', 'something that invokes emotion', 'positive, enjoyable and memorable', 'the customer must be your number one focus', 'etiquette', 'soft, sincere, caring, polite and positive', 'courteous, professional, experienced and polite', 'customers are the centre of attention', 'high standard experience'.

\section{Topics addressed in the Fitting Training Guide}

1. Background and additional information on things like breast cancer and the anatomy of the breast

2. The approach to bra fitting expected of the employees in the store

3. The features of the bra

4. Different styles of bras explained

5. Tone of voice to be used by employees

6. Atmosphere to be created in the fitting room

7. Potential scenarios and how to approach them

8. Customer is 'number one'

\section{Background and additional information}

- The bra fitting guidelines are set out in depth, covering each and every feature of the bra. They describe how the employee should approach each of these aspects, and how it should be described, to coincide with the training guidelines.

- The guidelines have pictures: if the bra is sitting like this then you would go up a cup size, go down a back size etc. The pictures aid the training manual as, in reality, it is a visual. Relying purely on words to describe how the bra is sitting would not suffice.

- Details and information on the anatomy of the breast, health and care and appropriate terminology to use, chosen by the company to be in line with their professional and informative manner.

\section{The approach to bra fitting expected of the employees in the store}

- The guide is introduced as to guiding the employees as to how to give the best 'experience' but they are encouraged to apply their personality and manner to the experience to make it unique to them.

- There are rules on approach and manner, e.g. 'polite, positive, and friendly, show empathy'.

- The bra fitting guidelines are branded, and this is the name by which the employees refer to them, both between themselves and to customers too, on occasion.

- The guidelines continue to provide in-depth detail on bra fitting in general e.g. the shape of the breast, style of bras and their names, fabrics and customer preferences. These are in great detail and are very helpful for understand the bust and other aspects to consider when bra fitting.

- Information and advice is the key to the experience and employees are encouraged to be as thorough as possible.

- The process is described thoroughly and in-depth so the employee can visualise how it would happen in reality. The process is friendly and knowledgeable. The approach is informative and the employee can put their own spin on things too, as long as they follow the steps, especially the vital steps that are highlighted.

\section{The features of the bra}

- The features of a bra, in a technical sense, are described for the employee to fully understand the parts of the bra and for them to refer to them during the fitting experience. 
- This section is again highly detailed. It is an 'extra information' area, so will only be addressed if the customer asks the employee specifically, except for the main features, which will always be mentioned during the experience.

- This heightens the overall knowledge of the employee in the area of lingerie and bra fitting.

\section{Different styles of bras}

- The training describes the different features of various styles of bras.

- The use for bras, the look achieved by these bras and their purpose is described.

- The preference of style for breast shape or by customer preference is described also.

- This helps the experience, as the employee can refer to the bras by their appropriate terminology and it encourages the customer to do so. The next time they come in they can say instantly, for example, ' $I$ love balconette styles, can you show me any new ones you have got in?'

- It also describes the type of clothing best suited to the style of bra.

\section{Tone of voice to be used by employees}

- Tone of voice: 'soft, sincere, caring, polite and positive'.

\section{Atmosphere to be created in the fitting room}

- There are details on 'etiquette' specifically for the fitting rooms.

- The experience must be 'positive, enjoyable and memorable'.

- Employees are instructed to be 'courteous, professional, experienced and polite' during the bra fitting experience to each and every customer that is in the fitting room despite all customers differences and situations, everyone must receive the same incredible service.

\section{Potential scenarios and how to approach them}

- The adaptability of the employee is stressed, in order to deal with difficult or 'not-your every-day' situations.

- Potential scenarios of this nature are described, and thorough instructions are given with regards to these types of customers.

- The thoroughness of the scenarios stress the sensitive and detailed approach that must be taken, highlighting key differences between the original approach and this tailored approach to the situation at hand.

- There is fine detail on potential situations and types of customer, to ensure the employee is equipped with the knowledge they require to appropriately deal with any situation and to fit the customer to the standard the customer expects of them.

- All possible scenarios receive the same level of service and attentiveness from the employee, although the approach may be tweaked slightly to tailor it to the customer's preferences and circumstances.

\section{Customer is number one}

- 'The customer must be your number one focus'

- 'Customers are the centre of attention', 'high standard experience'.

- Throughout the guidelines there is an emphasis on how important the customer is, and directions for the employee to put the customer first in each and every way. They must make the customer comfortable and relaxed.

- The customer must feel like they are in a positive environment when with the employee, who must listen to everything they say and tailor the service to them; for example, if they want a certain type of bra, if they are shy, or if they are completely lost, and need the employee to describe everything twice, to make sure they really understand and fully enjoy the experience. 


\section{Appendix II}

\section{Ethnographic Observations - Abbreviated Notes}

1. Diary of Participant Observer [PO]

- Saturday 1 December 2012 to Sunday 24 February 2013

- 21 entries

2. Team Talks

3. Daily Planner

4. Bra fitting

5. Bra tracker general points

6. Organisational Culture

- Customer Perspective

- Employee Perspective

7. The Staff meeting 


\section{Appendix III}

\section{$\underline{\text { Semi-Structured Interview Schedule }}$}

\section{Statement of Intent and Scope of Interview}

The research in which this interview material will be used to address is predominantly based on accounting. Narrowing it down from this area it falls under the category of management accounting, and has a central focus on how performance is measured. The performance measurement focused on will be the bra fit tracker which you as an employee interact with on a daily basis. I have chosen this performance measurement as I want to focus on the individual contribution of employees as opposed to performance measures at an organisational level e.g. market share. I feel it is important to understand why the individual is driven to work and perform well in their working environment. It appreciates the individual contribution and recognises that without each of the individual contributions across the company; it may not be successful today.

The second focus is on organisational culture. The questions will help determine what type of organisational culture exists in your work environment, how this affects motivation and interaction with the performance measure in question.

I will be trying to uncover your motivation to produce high performance levels. Performance in this interview is regarded as amount of sales; customers approached; retaining customers; and customers leaving happy after their service.

The questions cover these five areas:

- The performance measure - the bra fit tracker;

- The Organisational Culture within the company;

- Other organisational components which relate to the management control systems in place: planning; reward and compensation; and administrative controls.

At the end there will be some general questions on the role of accounting and your personal motivations towards bra fitting.

The interview will be semi-structured so at any point feel free to add extra points, take your time with question responses or request to not respond to a certain question. The interview will be recorded but you will remain anonymous in the research and the results will not be shared with anyone else in the company unless a copy is adamantly requested by head office. If you do not want to be recorded please state so now and I will take notes only when conducting the interview. I will be taking notes during the interview, I ask for your patience between questions as I take a moment to write down any notes I feel crucial to the study. The interview should take no more than two hours and I thank you very much in advance for your participation in my research.

\section{Interview Questions:}

\section{The Performance measure:}

- Can you describe the bra fit tracker to me?

From the information I have gathered through my observation and of course my participation in the company I will be regarding the performance measure in the vein of the following characteristics.

The bra fit tracker in place records your individual bra fit sales for the day. A target is created through the interaction of the manager and the individual employee. Feedback is provided at the next target setting date each week reflecting on the previous week addressing problems and planning for the next week. Sales are viewed by the manager and are sent to head office to monitor progress and the bra fitting elements contribution to overall sales. Comparisons are also made between stores. 
- Goal-setting theory: When you set the next weeks target with the manager do you feel your involvement in the process has an effect on your motivation to make your target?

- Agency theory: On occasion the tracker is linked with rewards and official company reward schemes; does the presence of a reward have an effect on your motivation to make sales? (Reward and Compensation)

- Do you always write down your bra fit sales? Explain your reasons for this.

- Would you improve the bra fit tracker in any way?

If so, how and why?

- The figures are viewed by your manager and are sent to head office; does this affect how hard you work to get bra fit sales? (Governance)

- Say you do not meet your target, does this drive you to work harder the next week or do you feel demotivated?

- If you feel de-motivated from this, what would increase your motivation again?

- Do you feel your individual contribution to the stores overall sales is significant? I use the word significant in the sense that your contribution matters rather than of significant amount.

- How about to the company's overall sales?

- Are there elements of your bra fitting experience with customers that your feel is not captured by the tracker but you feel are important? E.g. customer retention, honesty, tenderness in approach.

- Manager Question: How much emphasis do you place on the bra fit tracker?

- Manager Question: How important do you think the bra fit tracker is for driving sales?

- Manager Question: What do you think is the main driver of motivation and in turn performance for your employees?

- Manager Question: What other elements do you feel contribute to the sales made when bra fitting?

\section{Organisational culture:}

Organisational culture in this study is defined as 'the values, beliefs and social norms which are established within the company' (Malmi and Brown, 2008). It has also been regarded as "the way we do things around here" (Deal and Kennedy, 1982; Lee and Yu, 2004).

- Do you think there is an organisational culture in your workplace?

- Can you describe it to me?

- What elements make it different to current stores in the same industry or general retail stores?

- Are there differences between the organisational culture in this workplace than previous organisational cultures you have experienced through employment?

- Culture as a root metaphor: How do you think the organisational culture is created?

\section{Value-based controls:}

Value-based controls are defined as "the explicit set of organisational definitions that senior managers communicate formally and reinforce systematically to provide basic values, purpose, and direction for the organisation" (Simons, 1995; Malmi and Brown, 2008). An example is a mission statement (Malmi and Brown, 2008).

- What values do you think have been instilled in your approach to work by interaction with training programmes, mission statements or other formal company information?

- Do you feel any values have been created through employee interaction alone? Perhaps that makes your store unique from other stores in the brand.

- To what extent do you feel you contribute to or express the organisational culture?

\section{Symbols:}

Symbols in organisational culture are defined as "the visible expressions created by the organisation" (Schein, 1997; Malmi and Brown, 2008). Examples of visible expressions include building/workspace design and the necessity to wear a particular type of uniform. 
- What symbols are present in your workplace that you feel help create the organisational culture?

- Are there any symbols created by the individual employees? These may be symbols that make your store unique from other stores in the same brand.

\section{Clan controls:}

Clan controls in organisational culture are defined as "sub-cultures or micro-cultures or individual groups can be labelled as clans" (Ouchi, 1979; Malmi and Brown, 2008).

- Do you feel any "clans" are present?

- Between the lingerie industry and other retail stores.

- Between other stores in the same brand.

- Between sales assistants and managers in your own store.

- How do you feel this adds or takes away from the organisational culture?

\section{Planning:}

- Manager Question: What factors do you take into consideration when setting the targets with your employees?

- Manager Question: Do you take into consideration the overall sales target for the week when assigning your employees weekly bra fit targets?

\section{Reward and Compensation:}

- Do you feel a difference in motivation when rewards are unofficial e.g. a cupcake at the end of the day; or official through the company e.g. money/gift card based rewards?

- Manager Question: Why do you attach rewards to the bra fit trackers?

- Manager Question: Do you feel there is an increase in performance when rewards are attached?

- Manager Question: Do you feel there is a difference in performance when the rewards are unofficial e.g. a cupcake at the end of the day; or official through the company e.g. money/gift card based rewards?

\section{Administrative Controls:}

\section{Governance:}

Governance controls include "formal lines of authority and accountability (Abernethy and Chua, 1996) as well as the systems which are in place to ensure that representations of various functions and organisational units meet to co-ordinate their activities both vertically and horizontally" (Malmi and Brown, 2008).

- Manager Question: What motivates you to drive the employees to work harder?

- Manager Question: Do you want you the store to do well so that the store is positively regarded in meetings?

\section{Policies and Procedures:}

- What policies and procedures within the company do you feel contribute to the organisational culture?

- Your bra fitting selling skills are reviewed in your three month review; does this affect your performance towards bra fitting?

\section{Scenarios:}

\section{Scenario 1 - Performance measurement removed:}

Imagine the performance measure was removed, your motivation would reply on your own drive and the organisational culture. How do you think this would affect your bra fitting sales performance?

\section{Scenario 2 - Different organisational culture:}


Imagine the performance measure remained but the organisational culture was different. Imagine a culture where you wore your clothes, the training packs were not as detailed and the sales approach was not as thorough or illuminated in organisational material. Motivation would rely on the performance measure components and your own personal drive. Would you still be motivated to write sales down and provide good customer service (e.g. how is your performance affected)?

\section{Scenario 3 - A match made in heaven:}

Both the performance measure and the organisational culture at its current state remain. Do you feel with the presence of both factors creates your highest performance level?

\section{General Questions:}

The role of accounting in the workplace:

"In some organizations, accounting is centrally involved in work rituals: financial achievement is celebrated; budgets are massaged, pored over, and matter. In others, accounting is incidental, perhaps existing as a practice, but with no particular significance" (Dent, 1991).

- After listening to these two statements, do you feel accounting is central or incidental in your workplace?

- Why do you think the performance measure has been put in place by the company? (Nature of use Interactive/Diagnostic).

\section{Bra fitting:}

- Does bra fitting mean anything to you on personal level? Or is it just part of the job?

This is the end of the interview. I would like to thank you very much for your time and contribution to my research. If there are any other points you would like to make, please feel free to do so now. 